\title{
SCHOTTKY CONTRIBUTIONS IN CHEMICAL THERMODYNAMICS
}

\author{
E. F. Westrum, Jr. \\ DEPARTMENT OF CHEMISTRY, UNIVERSITY OF MICHIGAN \\ ANN ARBOR, MI 48109, U.S.A.
}

\begin{abstract}
Cryogenic heat-capacity determinations provide a useful tool for the determination of the energetic spectrum of condensed phases and also reveal information on their discrete electronic level structures as well. We have been interested in applying these techniques to actinide elements and have in recent months been working up the techniques to unravel the corresponding data for the lanthanide compounds-where opposite trends in cationic masses and molar volumes provide an opportunity to test theories useful for the resolution of excess heat capacity from lattice contributions.

As an important aspect of heat capacities-especially of compounds with $d$ and $f$ electronsthe Schottky contribution deserves to be much better known-by chemists, by physicists, and by students of thermodynamics. These remarks are designed to further that goal.
\end{abstract}

\section{Schottky's “Orphaned” contribution}

Werner Schottky first showed in 1922 [1] that a contribution to the energeticsspectroscopic or thermophysical - of a substance could be expected from excited electronic levels. The splitting of the ground-level term by the crystalline electric field also gives rise to the appearance of such a "Schottky anomaly" or "Schottky contribution" either in the heat capacity or in other thermophysical properties. The manifestation of this contribution to the heat capacity is a characteristic bellshaped curve skewed out on the high-temperature side. The temperature of the peak is related to the energetic separation of the levels and the maximum height is determined by the ratio of the degeneracies. Moreover, the total entropy under the curve is also related to the number of levels and the degeneracies involved. When the electronic energy increments are sufficiently small, the Schottky anomaly occurs at so low a temperature that, in comparison to the lattice contribution, the Schottky contribution stands out clearly. When energy levels are sufficiently spread so as to cause the occurrence of the contribution near or above ambient temperature, the maximum is typically so spread out as to be unrecognized unless the heat capacities of isostructural substances with nearly identical atomic masses are used for 
comparison. Nonetheless, the Schottky contribution does represent an important aspect of the morphology of the heat-capacity curves and tends to do so increasingly as higher temperatures are involved whenever one is dealing with transition-element, lanthanide-element, and actinide-element compounds.

Never again did he discuss the Schottly contribution. Schottly effects and Schottky defects occupied his career.

\section{Brief mathematical interlude}

The Schottky heat-capacity function, Sch $(u)$, is rigorously related to an Einstein heat-capacity function, Ein $(u)$, by both an additive and a multiplicative identity:

$$
\operatorname{Ein}(u)-\operatorname{Ein}(2 u)=\operatorname{Sch}(u) \text { and } \operatorname{Ein}(u) \operatorname{Sch}(u)=u^{2} \operatorname{Ein}(2 u) \text {. }
$$

These by no means exhaust the family of rigorous relationships, and in the course of considerable experimentation with the mathematics of these functions we have deduced about 40 equations to deal with two-level Schottky functions with equal degeneracies and-at the present time - with integral arguments. For the more difficult-and far more useful - cases of many levels, differing degeneracies, and non-integral arguments (which differ from each other by a per cent or so) we have been obliged to use-with somewhat less rigor-series approximations or numerical evaluation.

Some of my friends claim to find evidence for Schottky functions by differencing the heat capacities of a compound and its diamagnetic analog (utilized as a lattice contribution). In these instances the difference is indeed proably exactly a Schottky function, but it is occasioned simply by the fact that the Einstein or Debye thetas of the two substances differ slightly, and the apparent Schottky contribution is an artifact occasioned simply by the additive identity already presented. Moreover, the difference between the heat capacities of a vitreous phase and the corresponding crystal (e.g., $\mathrm{B}_{2} \mathrm{O}_{3}$ ) is also - for somewhat the same reasons--a Schottky function.

\section{A byte on morphology}

The Schottky function is a beast that is a little hard to "fudge". Its shape is totally determined by the levels and the degeneracies. In the simple system already discussed, maximum height is independent of the temperature and is governed only by the degeneracies. In a system with more energy levels, the shape of the anomaly is determined, of course, by the overall pattern of energy levels. Calculations for the 
simple case of only two levels can be made by the following equation:

$$
C_{\text {Schotky }} / R=u^{2}\left(g_{0} g_{1}\right) \exp u /\left\{\left(1+g_{0} / g_{1}\right) \exp u\right\}^{2} ; \quad u=e / k T .
$$

It is interesting to note in passing that the Schottky heat capacity for a two-level equidegenerate system can also be represented by the equation:

$$
C_{\text {Schonky }} / R=\frac{u}{2} \operatorname{sech} \frac{u^{2}}{2} .
$$

A simple, symmetrical formula designed to obfuscate the reader!

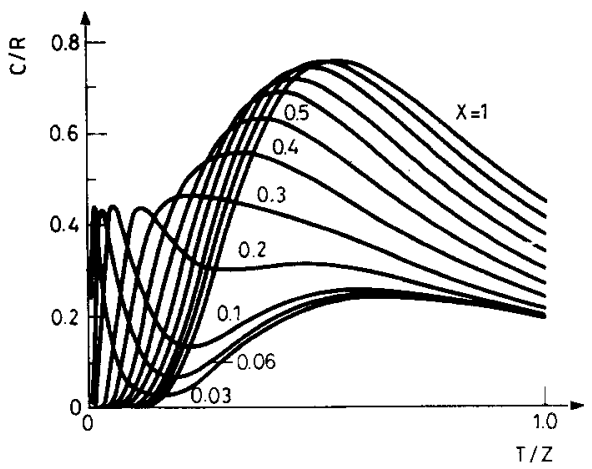

Fig. 1 Schottky functions for 3 equidegenerate level systems related to the parameters, $X=\left(E_{1}-E_{0}\right) /\left(E_{2}-E_{0}\right)$ and $Z=E_{2}-E_{0}$

The morphology of three-level system curves is shown in Fig. 1 for a variety of values of the ratio of energies between the two levels.

\section{Lanthanide Schottky lore}

Although none of the examples Schottky gave in his original paper were indeed other than poor heat-capacity measurements and not true examples of Schottky contributions, real Schottky contributions have been measured on occasion since the early 1930's by calorimetrists, most often on magnetically dilute materials. Recognition of the importance of the Schottky thermophysical contribution came with a 1963 series of papers by Justice and Westrum [2] who studied the lanthanide sesquioxides and obtained an unusually rich yield of data concerning the energetics of the trivalent ions in these compounds. Although the Schottky contributions may also be studied spectroscopically, the general unavailability of single crystal samples for absorption spectroscopy or for paramagnetic resonance experiments have tended to favor the calorimetric approach. Our initial measurements [2] on 
neodymium sesquioxide led to the estimation of levels more than an order of magnitude smaller than those estimated by Penny [3] from crystal-field splittings, but later, other spectroscopy [4] confirmed, in this instance, the calorimetric values.

Subsequently, Sommers and Westrum examined most of the lighter lanthanide trichlorides [5]. Their study further heightened the understanding of the trends and regularities involved and showed the importance of the Schottky contribution to the thermophysical functions. These functions were in excellent accord with those predicted by the scheme of Westrum [6] based upon the treatment of Grønvold and Westrum [7]. Chirico and Westrum [8] studied the trihydroxides and developed as well as tested the "volumetric scheme" for the resolution of lattice and excess heatcapacity contributions.

\section{Lanthanide sesquisulfides-an example}

To exemplify the resolution technique I would like to discuss briefly recent work on four $\gamma$-phase preparations of lanthanide sesquisulfides- $\mathrm{La}_{2} \mathrm{~S}_{3}, \mathrm{Ce}_{2} \mathrm{~S}_{3}, \mathrm{Nd}_{2} \mathrm{~S}_{3}$, and $\mathrm{Gd}_{2} \mathrm{~S}_{3}$. Interpretation of the observed phenomena, taking account of crystalfield effects and available lower temperature heat-capacity data $[9,10]$, permits evaluation of the thermodynamic functions and resolution of the Schottky contributions together with correlation with infrared and Raman scattering data presented in the literature [9-12].

Sample provenance. The sulfides were prepared at the Ames Laboratory, Iowa State University, by direct combination of high-purity elements prepared in the Ames Laboratory [13] in a manner similar to that described by Gschneidner et al. [14] with sublimed sulfur $(99.999 \%)$. The quartz ampoules were opened and the sulfide was ground and sieved to 200 mesh powder, cold-pressed into pellets, and heated under a dynamic $\mathrm{H}_{2} \mathrm{~S}$ atmosphere for 24-48 hours.

Automated adiabatic calorimetry. The data were taken in the Mark X calorimetric cryostat, a version of the Mark II cryostat improved by addition of a guard shield surrounding the adiabatic shield. The cryostat and the relevant operating techniques have been described previously [15]. The operation of the instruments and the acquisition of heat-capacity data from about 7 to $350 \mathrm{~K}$ was computerassisted. Temperatures and other accurate experimental quantities are referred to standards provided by the National Bureau of Standards.

Schottky heat-capacity contributions. Resolution of Schottky contributions from heat-capacity data on lanthanide compounds requires an accurate determination of the much larger "lattice" contribution. The heat-capacity volume-weighted latticeapproximation technique employed here has been used successfully in several other 
groups of lanthanide compounds [16] and involves linear interpolation between diamagnetic $\mathrm{La}_{2} \mathrm{~S}_{3}$ and $\mathrm{Gd}_{2} \mathrm{~S}_{3}$ with the magnetic contribution deleted. Largely unpublished infrared spectra on powdered mull samples were taken by Henderson et al. [12].

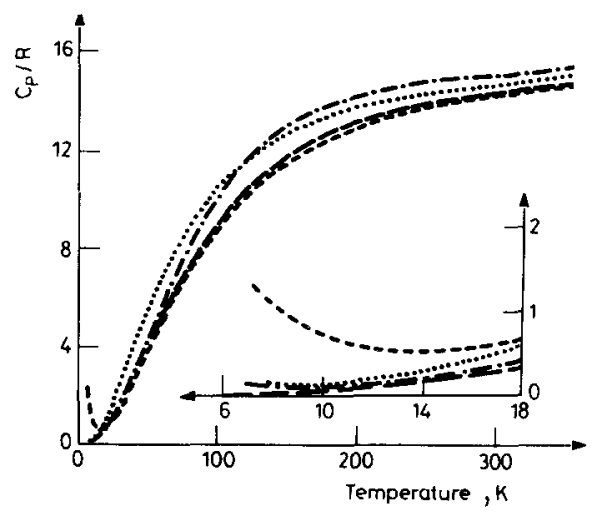

Figí 2 Molar heat capacities of $\mathrm{La}_{2} \mathrm{~S}_{3}, \mathrm{Ce}_{2} \mathrm{~S}_{3}, \mathrm{Nd}_{2} \mathrm{~S}_{3}$, and $\mathrm{Gd}_{2} \mathrm{~S}_{3}$. Total heat-capacity curves for $\mathrm{La}_{2} \mathrm{~S}_{3}$ $(\ldots \ldots .),. \mathrm{Ce}_{2} \mathrm{~S}_{3}(-\cdot-), \mathrm{Nd}_{2} \mathrm{~S}_{3}(-\cdots)$, and $\mathrm{Gd}_{2} \mathrm{~S}_{3}(--)$
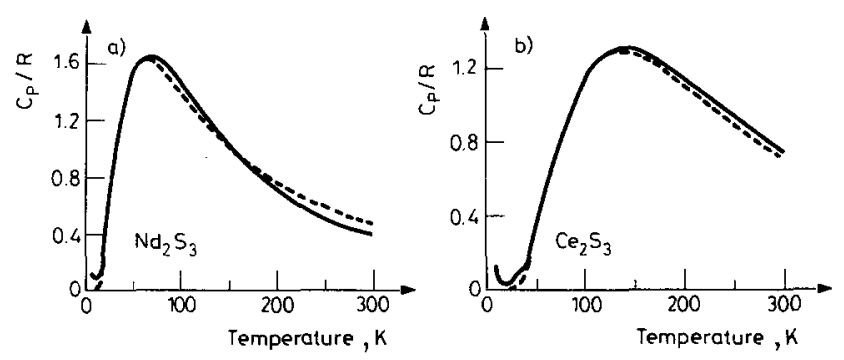

Fig. 3 (a, b) Calorimetric Schottky contributions for $\mathrm{Nd}_{2} \mathrm{~S}_{3}$ and $\mathrm{Ce}_{2} \mathrm{~S}_{3}$ based on volumetric scheme interpolating between $\mathrm{La}_{2} \mathrm{~S}_{3}$ and $\mathrm{Gd}_{2} \mathrm{~S}_{3}$ (with corrections for magnetic ordering ) (- $\longrightarrow$ ). Spectroscopic contributions from Stark levels (---)

The (total) heat capacity curves for the four substances are displayed in Fig. 2, although only that for $\mathrm{La}_{2} \mathrm{~S}_{3}$ has been populated with experimental points. Taking into account all of the available spectroscopic data and the results of lattice sum calculation of $\mathrm{Ce}_{2} \mathrm{~S}_{3}$ has led us to the identification of the doublet levels of 0,185 , and $353 \mathrm{~cm}^{-1}$. The heat-capacity Schottky function defined by these points is shown in Fig. 3a and excellent agreement is observed over the peak part of the range. $S$ :milarly for $\mathrm{Nd}_{2} \mathrm{~S}_{3}$, the Stark doublet levels of $0,76,150,180$, and $358 \mathrm{~cm}^{-1}$ provide an excellent fit with the calorimetric values as shown in Fig. 3 b. 


\section{Conclusions}

The extended application of this approach to Schottky contributions will further enhance our knowledge of electronic levels, splitting of ground terms by crystalline electric fields, and general systematics in lanthanide, actinide, and transitionelement compounds. The further extension of the volumetric scheme should not only enable additional heat-capacity resolution but also enhance greatly our ability to extrapolate - and interpolate-heat capacities for other isostructural substances (and even for substances with less well-related structures). Then, by incorporating calculated Schottky-and/or other excess contributions-total heat capacities may be more reliably evaluated.

\section{References}

1 W. Schottky, Phys. Z., 23 (1922) 448.

2 B. H. Justice and E. F. Westrum, Jr. (et al.), J. Phys. Chem., 67 (1963) 339; jibid., (1963) 345; ibid., (1963) 659; ibid., 73 (1969) 333; ibid., (1969) 1959.

3 W. G. Penny, Phys. Rev., 43 (1933) 2515.

4 J. R. Henderson, M. Muramoto and J. B. Gruber, J. Chem. Phys., 46 (1967) 2515.

5 J. A. Sommers and E. F. Westrum, Jr, J. Chem. Thermodynamics, 8 (1976) 1115; ibid., 9 (1977) 1

6 E. F. Westrum, Jr., in Lanthanide/Actinide Chemistry, R. F. Gould, Am. Chem. Soc., Washington, 1967, p. 25.

7 F. Grønvold and E. F. Westrum, Jr., Inorg. Chem., 1 (1962) 36.

8 R. D. Chirico and E. F. Westrum, Jr. (et al.), J. Chem. Thermodinamics, 11 (1979) 835; ibid., 12 (1980) 71; ibid., (1980) 311.

9 J. C. Ho and S. M. A. Taher, et al., J. Phys. 8 (1978) C6-840.

10 S. M. A. Taher, J. C. Ho and J. B. Gruber, J. Chem. Phys., 76 (1982) 609.
11 J. R. Henderson and M. Muramoto, et al, I. Chem. Phys. 52 (1970) 2311.

12 J. B. Gruber, J. R. Henderson and $M$. Muramoto, unpublished infrared spectra of rare earth sesquisulfides, McDonnell Douglas Astronautics Company, Santa Monica, CA (see, for example, reports DAC-59368P, Oct. 1966; DAC-605317R, June 1968).

13 T. G. Arkatroa and V. P. Zhuze, et al., Sov. Phys. Solid State, 21 (1979) 1979.

14 K. A. Gschneidner, Jr. and B. J. Beaudry, et al., Phys. Rev., B24 (1981) 7187.

15 E. F. Westrum, Jr, J. Chem. Educ., 39 (1962) 443. E. F. Westrum, Jr., G. T. Furukawa and J. P. McCullough, in Experimental Thermodynamics Vol. I, J. P. McCullough, D. W. Scott, Butterworths, London, 1968, p. 133. Cf. also E. F. Westrum, Jr., in Proceedings NATO Advanced Study Institute on Thermochemistry at Viana du Castello, Portugal, M.A.V. Ribeiro da Silva, New York, 1984, p. 745.

16 E. F. Westrum, Jr., J. Chem. Thermodynamics, 15 (1983) 305. 
Zusammenfassung - Bestimmungen der kryogenen Wärmekapazität sind nützlich zur Bestimmung des energetischen Spektrums kondensierter Phasen und liefern zugleich Informationen über deren diskrete Elektronenniveaustrukturen. Wir waren an der Anwendung dieser Techniken auf Actinidenelemente interessiert und haben in den letzten Monaten Methoden zur Ordnung der entsprechenden Daten für die Lanthaniden-Verbindungen ausgearbeitet - wo entgegengesetzte Trends von Kationenmasse und molarem Volumen die Möglichkeit bieten, Theorien zu prüfen, die nützlich für die Absonderung der Überschußwärmekapazität von Gitterbeiträgen sind. Als ein wichtiger Aspekt von Wärmekapazitäten, besonders von Verbindungen mit d- und f-Elektronen, sollte der Schottky-Beitrag von Chemikern. Physikern und Studenten der Thermodynamik besser verstanden werden. Diese Bemerkungen sollen diesem Zwecke dienen.

Резюме - Данные измерения теплоемкостей при низких температурах являются полезными для определения энергетического спектра конденсированных фаз, а также дают информацию о дискретной структуре электронных уровней. Ранее авторы применили этот метод к элемснтам актиноидного ряда, а совсем недавно для объяснения соответствующих данных для лантанондов, где противоположные тенденции величин катионов и молярных объёмов предоставляют удобный случай проверки теорий, используемых при выделении избыточной теплоемкости, обусловленной решетонными вкладами. Одним из важных аспектов теплоемкостей, в особенности для элементов с d- и f-электронами, является вклад дефектов Шоттки, заслуживаюших намного лучшего понимания термодинамики химиками, физиками и студентами. 